\title{
Safety Evaluation of a Hybrid Substructure for Offshore Wind Turbine
}

\author{
Min-Su Park, Youn-Ju Jeong, Young-Jun You, and Yoon-Koog Hwang \\ Structural Engineering Research Institute, Korea Institute of Civil Engineering and Building Technology, \\ 283 Goyangdae-ro, Ilsanseo-gu, Goyang-si, Gyeonggi-do 10223, Republic of Korea \\ Correspondence should be addressed to Min-Su Park; mspark@kict.re.kr
}

Received 18 May 2016; Accepted 26 July 2016

Academic Editor: Sung-Cheon Han

Copyright (C) 2016 Min-Su Park et al. This is an open access article distributed under the Creative Commons Attribution License, which permits unrestricted use, distribution, and reproduction in any medium, provided the original work is properly cited.

\begin{abstract}
Towers and rotor-nacelles are being enlarged to respond to the need for higher gross generation of the wind turbines. However, the accompanying enlargement of the substructure supporting these larger offshore wind turbines makes it strongly influenced by the effect of wave forces. In the present study, the hybrid substructure is suggested to reduce the wave forces by composing a multicylinder having different radii near free surface and a gravity substructure at the bottom of the multicylinder. In addition, the reaction forces acting on the substructure due to the very large dead load of the offshore wind turbine require very firm foundations. This implies that the dynamic pile-soil interaction has to be fully considered. Therefore, ENSOFT Group V7.0 is used to calculate the stiffness matrices on the pile-soil interaction conditions. These matrices are then used together with the loads at TP (Transition Piece) obtained from GH-Bladed for the structural analysis of the hybrid substructure by ANSYS ASAS. The structural strength and deformation are evaluated to derive an ultimate structural safety of the hybrid substructure for various soil conditions and show that the first few natural frequencies of the substructure are heavily influenced by the wind turbine. Therefore, modal analysis is carried out through GH-Bladed to examine the resonance between the wind turbine and the hybrid substructure.
\end{abstract}

\section{Introduction}

Offshore wind energy has gained attention in many countries as an alternative and reliable energy source since its potential has been recognized for long and mostly associated to the concept of nondestructive renewable energy. Therefore, many offshore wind farms are in the planning phase like in Europe, where wind farms will be established at greater water depths with larger turbines. In addition, towers and rotor-nacelles are being enlarged to respond to the need for higher gross generation of wind turbines. However, the accompanying enlargement of the substructure supporting these larger offshore wind turbines makes it strongly influenced by the effect of wave forces, which requires adopting new concepts for the substructure. Various substructures are available for the offshore wind turbines, such as the monopole, gravitybased structure, tripod, suction bucket, jacket, and floating platform. The type of substructure for the offshore wind turbine mainly depends on the water depth, turbine size, and soil conditions and has been studied by many researchers [1-6].
So far, less than twenty tripods have been installed in Europe. Thirty jacket foundations will also be installed at the Ormonde wind farms. Zaaijer [7] analyzed different substructures for a $6 \mathrm{MW}$ wind turbine in $20 \mathrm{~m}$ water depth. Føreland et al. [8] designed mono-pile, gravity-based structure, jacket, and three-pile fixed support structures for 2.5, 5 , and $10 \mathrm{MW}$ wind turbines for different water depths to quantify the economic differences provided by different wind turbine foundation systems for the environmental conditions of the North Sea.

The southwestern coast of the Korean peninsula is one of the most suitable places for the construction of offshore wind turbines. However, it is difficult to determine a proper substructure type because of the water depth range between 20 and $30 \mathrm{~m}$ and the very soft clay layer constituting the seabed in this area. This implies that a new substructure type suitable for the environmental characteristics of the southwestern coast of Korea must be developed.

In the present study, the hybrid substructure is suggested for the offshore wind turbines to be installed in 

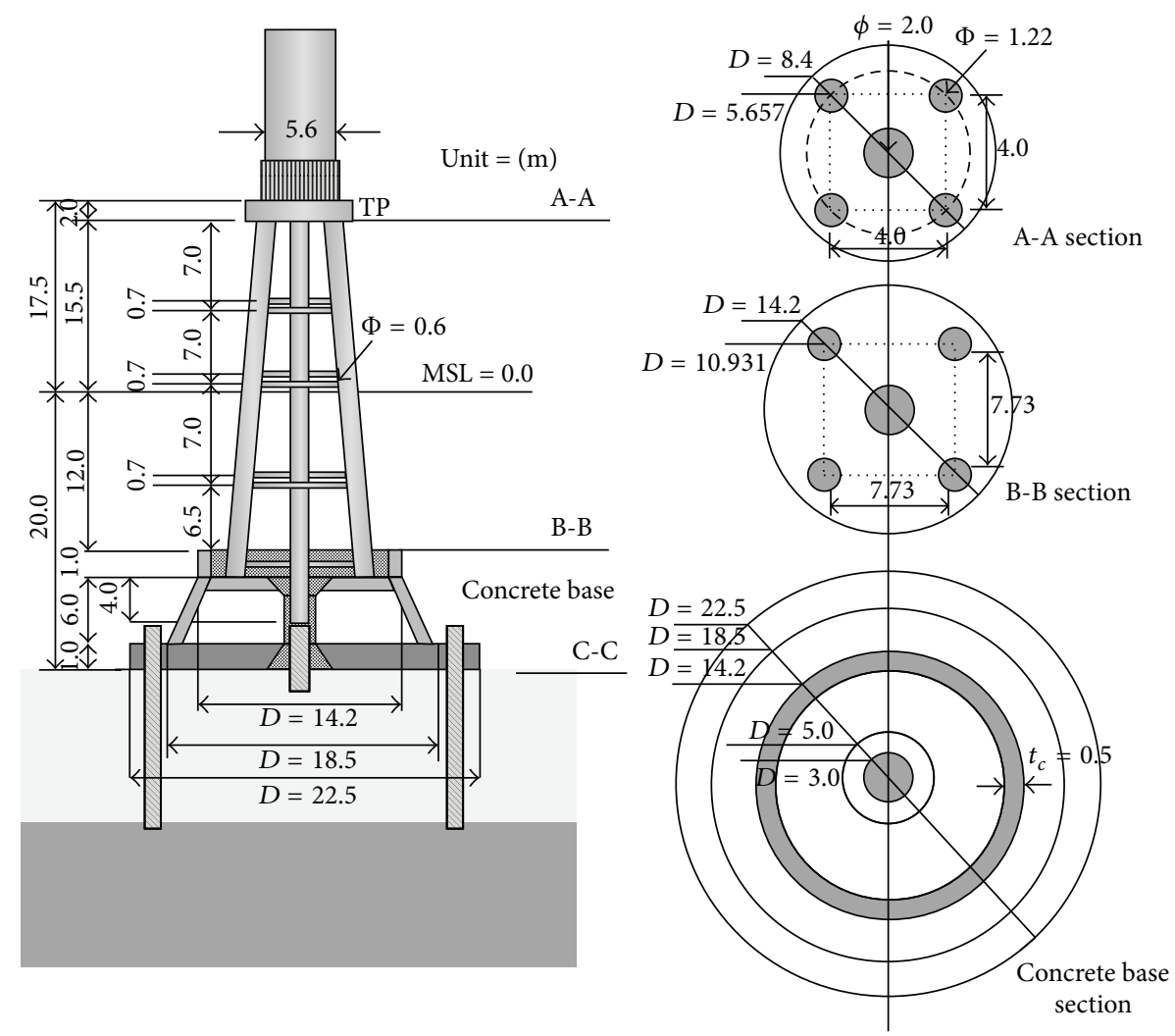

FIgURE 1: Geometrical configuration of the hybrid substructure.

the Korean southwest offshore wind project by composing a multicylinder having different radii near free surface and a gravity substructure at the bottom of the multicylinder [9]. In addition, the reaction forces acting on the substructure due to the very large dead load of the offshore wind turbine require very firm foundations. Therefore, the pile-soil interaction model should be adequately chosen according to the analysis type by performing sensitivity analysis. Some guidelines such as DNV, API, and GL recommend the use of the full nonlinear model for extreme load cases and foundation design. In this study, the ENSOFT Group V7.0 is used to calculate the stiffness matrices for the pile-soil interaction conditions and these matrices are then used together with the loads at TP (Transition Piece) obtained from GH-Bladed for the structural analysis of the hybrid substructure by ANSYS ASAS. The structural strength and deformation are evaluated to derive an ultimate structural safety of the hybrid substructure for various soil conditions and show that the first few natural frequencies of substructure are heavily influenced by the wind turbine. Therefore, the first natural frequency of the substructure must be within the soft-stiff range in between the rotor frequency (1P) and the blade passing frequency (3P). Therefore, modal analysis is carried out through GH-Bladed to investigate the resonance between the wind turbine and the hybrid substructure. It is found that the suggested hybrid substructure can be effective for reducing the hydrodynamic effects and construction costs in the southwestern sea of South Korea.
TABLE 1: Details of 3.0 MW wind turbine model.

\begin{tabular}{lcc}
\hline Turbine parameters & Unit & Value \\
\hline Rated power & $\mathrm{MW}$ & 3.0 \\
Configuration & - & 3 blades \\
Design wind class & - & IEC IA \\
Rotor diameter & $\mathrm{m}$ & 91.3 \\
Hub height & $\mathrm{m}$ & 80 \\
Cut-in speed & $\mathrm{m} / \mathrm{s}$ & 3 \\
Cut-out speed & $\mathrm{m} / \mathrm{s}$ & 25 \\
Rated wind speed & $\mathrm{m} / \mathrm{s}$ & 13 \\
Rated rotor speed & $\mathrm{rpm}$ & 15.7 \\
\hline
\end{tabular}

\section{Numerical Model and Environmental Conditions}

2.1. Wind Turbine and Substructure Model. In the present study, the $3.0 \mathrm{MW}$ wind turbine model of Doosan Heavy Industries is selected for the structural safety analysis of the hybrid substructure. The details of this wind turbine are provided in Table 1.

The height of the hybrid substructure is $37.5 \mathrm{~m}$ from seabed and the water depth (MSL) is $20.0 \mathrm{~m}$ as shown in Figure 1. Since the water particle velocity is the largest near free surface, the hybrid substructure is composed of a multicylinder having different radii near free surface to reduce the wave forces acting on the substructure and a gravity-based 
TABLE 2: Dimensions of multicylinder (mm).

\begin{tabular}{lcccc}
\hline \multirow{2}{*}{ Multicylinder } & \multicolumn{2}{c}{ Cylinder part } & \multicolumn{2}{c}{ Joint part } \\
& Diameter & Thickness & Diameter & Thickness \\
\hline Side cylinder & 1220 & 30 & 1224 & 32 \\
Center cylinder & 2000 & 25 & 2024 & 37 \\
Brace & 600 & 20 & 624 & 32 \\
\hline
\end{tabular}

TABle 3: Properties of materials.

\begin{tabular}{lcc}
\hline & Steel & Concrete \\
\hline Density $\left(\mathrm{kg} / \mathrm{m}^{3}\right)$ & 7850 & 2500 \\
Young's modulus $\left(\mathrm{N} / \mathrm{m}^{2}\right)$ & $2.0 \times 10^{11}$ & $3.0 \times 10^{10}$ \\
Shear modulus $\left(\mathrm{N} / \mathrm{m}^{2}\right)$ & $7.692 \times 10^{10}$ & $1.271 \times 10^{10}$ \\
\hline
\end{tabular}

substructure at the bottom of the multicylinder to increase the stability against overturning moment. The multicylinder and the gravity-based substructure are, respectively, made of steel and concrete with $0.5 \mathrm{~m}$ thickness. The main dimensions and characteristics of the hybrid substructure are listed in Tables 2 and 3.

2.2. Design Load Cases and Environmental Conditions. The structural safety analysis adopts design code IEC 61400-3 [10] and is carried out according to the ultimate design load cases (DLC) presented in Table 4.

The wind and wave for the southwestern sea of South Korea are presented in Table 5. In Table 5, FLS stands for fatigue limit state and ULS for ultimate limit state. The data at the selected site measured from July, 1979, to December, 2010, are used to estimate the extreme wind and wave conditions with return period of 50 years according to IEC61400-1 design standard. The extreme current velocities at free surface and seabed are $1.05 \mathrm{~m} / \mathrm{s}$ and $0.54 \mathrm{~m} / \mathrm{s}$, respectively.

2.3. Stiffness for Pile-Soil Interaction. The interaction between the superstructure and foundation system intensifies with larger mass of the substructure. This indicates that this interaction contributes increasingly to the structural response of the total system increases. Based on the soil condition at the selected site, the stiffness matrices for the pile-soil interaction conditions are calculated using ENSOFT Group V7.0. The corresponding stiffness for the pile-soil interaction foundation system is provided in Tables 7-10.

\section{Numerical Results and Discussion}

3.1. Natural Frequencies and Resonance. For a modern wind turbine, the design criterion for the natural vibration characteristics of the offshore wind turbine is the so-called softstiff design. In this case, the lowest natural frequencies of the complete system fore-aft or side-to-side are adjusted so that they remain above the rotational frequency (1P) and below the blade passing frequency (3P) for the entire operating range of the turbine [11]. In order to evaluate the resonance between the wind turbine and the hybrid substructure, modal analysis is carried out through GH-Bladed for pile-soil interaction and fixed foundation system.

Table 11 and Figure 2 arrange, respectively, the natural frequencies and the mode shapes of the hybrid substructures considering pile-soil interaction and fixed foundation. The difference in the first mode frequency between pile-soil interaction and fixed condition is about $4.3 \%$. Since the coupled stiffness between forces and moments is not considered in this study, the difference becomes larger for higher modes. In addition, the dynamic responses of the hybrid substructure are slightly influenced by this effect. Figure 3 plots the natural frequency of the hybrid substructure system obtained from modal analysis with respect to the spectrum density of the turbine and the wave condition. It is found that the natural frequency of the hybrid substructure system stands between the turbine's natural frequency (1P) and the blade's passing frequency (3P). Accordingly, there is no possibility of resonance to occur between the wind turbine and the hybrid substructure.

3.2. Wave Force Evaluation. Figures 4 and 5 compare, respectively, the wave forces and the wave moments of the hybrid substructure and the mono-pile for various water depths. The properties of the mono-pile are based on Espinosa's model [12] and its diameter is $6 \mathrm{~m}$. The water depths corresponding to the lowest still water level (LSWL), mean sea level (MSL), and highest still water level (HSWL) are $15.44 \mathrm{~m}, 20.00 \mathrm{~m}$, and $24.56 \mathrm{~m}$, respectively. In the comparison, the calculated total wave forces are divided by the incident wave amplitude $(H / 2)$ and the wave moments are calculated at seabed. Since the wave force is closely related to the wetted surface of the substructure and the largest water particle velocity occurs near free surface, the wave forces and moments on the monopile increase gradually with larger water depth. The largest wave forces on the hybrid substructure are observed at LSWL because the gravity-based substructure is located at seabed. However, the wave forces on the hybrid substructure decrease gradually with larger water depth due to the reduction of the wave forces acting on the gravity-based substructure with increasing water depth. This indicates that installing the multicylinder near free surface can be effective for decreasing the wave forces. The peak wave forces at MSL and HSWL decrease by about $19 \%$ and $32 \%$ compared to the peak value at LSWL. Moreover, the suggested hybrid substructure appears to be very effective for increasing the stability against overturning moment since the hybrid substructure experiences extremely small variation compared to the large variation encountered by the mono-pile.

3.3. Structural Results. The dynamic responses of the offshore wind turbine supported by the hybrid substructure are investigated for various design load cases (DLC) based on IEC 61400-3 [10] design code. The loads at TP (Transition Piece) obtained from GH-Bladed are presented in Table 12. In the present study, the values at TP for DLC 6.2ja-2 (idling with grid loss condition) are used because they are the largest among all the DLC. Figures 6 and 7 show the time histories of the forces and the moments at TP. 
TAble 4: Design load cases (DLC) for ultimate limit state.

\begin{tabular}{|c|c|c|c|}
\hline$\overline{\mathrm{DLC}}$ & Condition & Wave & Wind \\
\hline 1.1 & Power production & Normal & Normal \\
\hline 1.3 & Power production & Normal & Extreme \\
\hline 1.4 & Power production & Normal & Extreme \\
\hline 1.5 & Power production & Normal & Extreme \\
\hline $1.6 \mathrm{a}$ & Power production & Severe & Normal \\
\hline 2.1 & Power production + control system fault & Normal & Normal \\
\hline 2.2 & Power production + occurrence of fault & Normal & Normal \\
\hline 2.3 & $\begin{array}{l}\text { Power production }+ \text { loss of electrical grid } \\
\text { connection }\end{array}$ & Normal & Extreme \\
\hline 4.2 & Normal shut-down + deterministic gust & Normal & Extreme \\
\hline 5.1 & Emergency shut-down & Normal & Normal \\
\hline $6.1 \mathrm{a}$ & Idling & Extreme & Extreme \\
\hline $6.2 \mathrm{a}$ & Idling with grid loss & Extreme & Extreme \\
\hline $6.3 \mathrm{a}$ & Idling with extreme yaw misalignment & Extreme & Extreme \\
\hline 7.1a & Idling with pitch failure & Extreme & Extreme \\
\hline 8.1 & Transport, assembly, maintenance, and repair & Normal & $15 \mathrm{~m} / \mathrm{s}$ \\
\hline
\end{tabular}

\begin{tabular}{|c|c|c|c|c|c|}
\hline & Mode 1 & Mode 2 & Mode 3 & Mode 4 & Mode 5 \\
\hline Pile-soil & 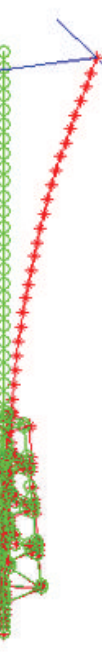 & 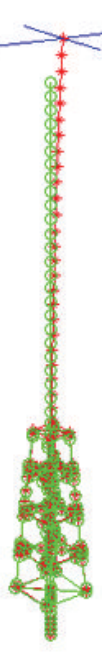 & $\begin{array}{l}3 \\
8 \\
8\end{array}$ & 2 & 霖 \\
\hline Fixed & 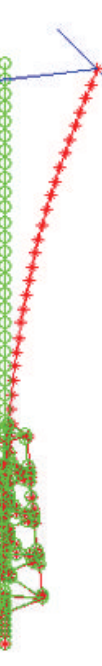 & 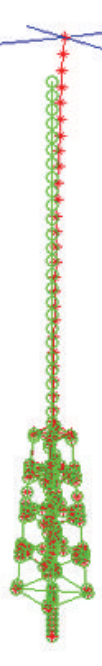 & $\frac{1}{4}$ & 4 & 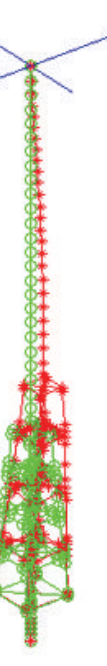 \\
\hline
\end{tabular}

FIGURE 2: Comparison of mode shapes of hybrid substructure. 


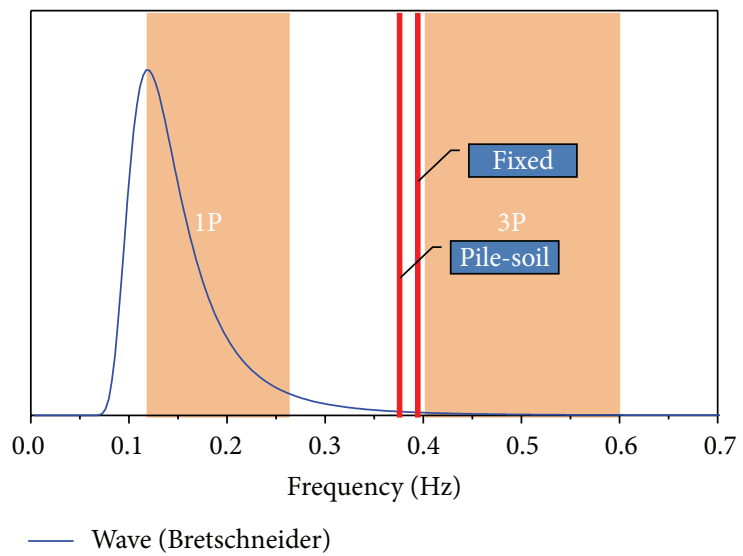

FIGURE 3: Comparison of hybrid substructure on the spectrum density of wind turbine and wave.

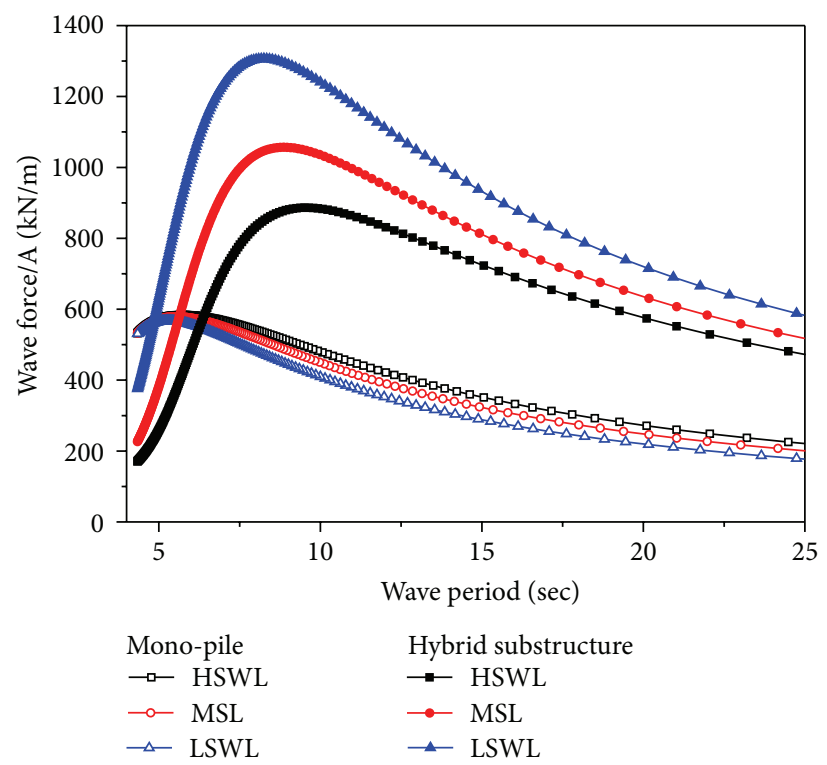

FIGURE 4: Comparison of wave forces for various water depths.

TABLE 5: Environmental conditions.

\begin{tabular}{|c|c|c|c|}
\hline & Wind & Wave & Limit state \\
\hline Normal & $6.90 \mathrm{~m} / \mathrm{s}$ & $\begin{array}{l}H_{s}=1.48 \mathrm{~m} \\
T_{p}=6.25 \mathrm{sec}\end{array}$ & FLS \\
\hline Extreme & $42.99 \mathrm{~m} / \mathrm{s}$ & $\begin{array}{c}H_{s}=6.87 \mathrm{~m}, \\
T_{p}=13.70 \mathrm{sec}\end{array}$ & ULS \\
\hline Extreme design & $42.99 \mathrm{~m} / \mathrm{s}$ & $\begin{array}{l}H_{d}=12.78 \mathrm{~m} \\
T_{p}=13.70 \mathrm{sec}\end{array}$ & ULS \\
\hline
\end{tabular}

Using the wind loads at TP and the stiffness matrices for pile-soil foundation system, the structural analysis of the hybrid substructure is carried out for various water depths using ANSYS ASAS. The 9th-order stream function wave theory is adopted to model the design wave that is regular wave with $H=12.78 \mathrm{~m}$ and $T=13.76 \mathrm{sec}$. The structural results are summarized in Table 13. A safety factor of 1.35 is applied for all cases. The displacements with pile-soil condition are larger than those with fixed condition but the results exhibit very different patterns. The displacement and the bending moment at MSL are largest in all cases since the middle brace is strongly influenced by the wave forces. The combined stress is concentrated at the connecting part between the multicylinder and the concrete cone and shows also large variation. Therefore, this connecting part should be examined explicitly in order to achieve reliable design of the substructure. The structural displacement and the bending moment at MSL are plotted in Figures 8-11 for various soil conditions. Since the loads at TP are larger than the wave forces acting on the substructure, the time histories of the displacement and bending moment do not present regular pattern, which means that the substructure is mainly influenced by the wind forces acting on the offshore wind turbine.

The JONSWAP wave spectrum is used to model irregular wave condition with $H=6.87 \mathrm{~m}$ and $T=13.70 \mathrm{sec}$. The JONSWAP wave spectrum was developed during the Joint 
TABLE 6: Soil conditions.

\begin{tabular}{lccccc}
\hline & $\begin{array}{c}\text { Depth } \\
(\mathrm{m})\end{array}$ & $\begin{array}{c}\text { SPT } \\
(\mathrm{N})\end{array}$ & $\begin{array}{c}\text { Density } \\
\left(\mathrm{kN} / \mathrm{m}^{3}\right)\end{array}$ & $\begin{array}{c}\text { Adhesion } \\
(\mathrm{kPa})\end{array}$ & $\begin{array}{c}\text { Internal friction } \\
\text { angle }\left(^{\circ}\right)\end{array}$ \\
\hline Silty sand & $0.0 \sim 7.5$ & $5 / 30 \sim 16 / 30$ & 19.0 & - & 27.5 \\
Silty clay & $7.5 \sim 10.5$ & $4 / 30 \sim 12 / 30$ & 18.5 & - & - \\
Silty sand & $10.5 \sim 24.3$ & $24 / 30 \sim 50 / 27$ & 19.0 & 25 & 38 \\
Weathered soil & $24.3 \sim 27.0$ & $50 / 15$ & 19.0 & 34 & 31 \\
Weathered rock & $27.0 \sim 34.0$ & $50 / 7 \sim 50 / 3$ & 21.0 & & 32 \\
\hline
\end{tabular}

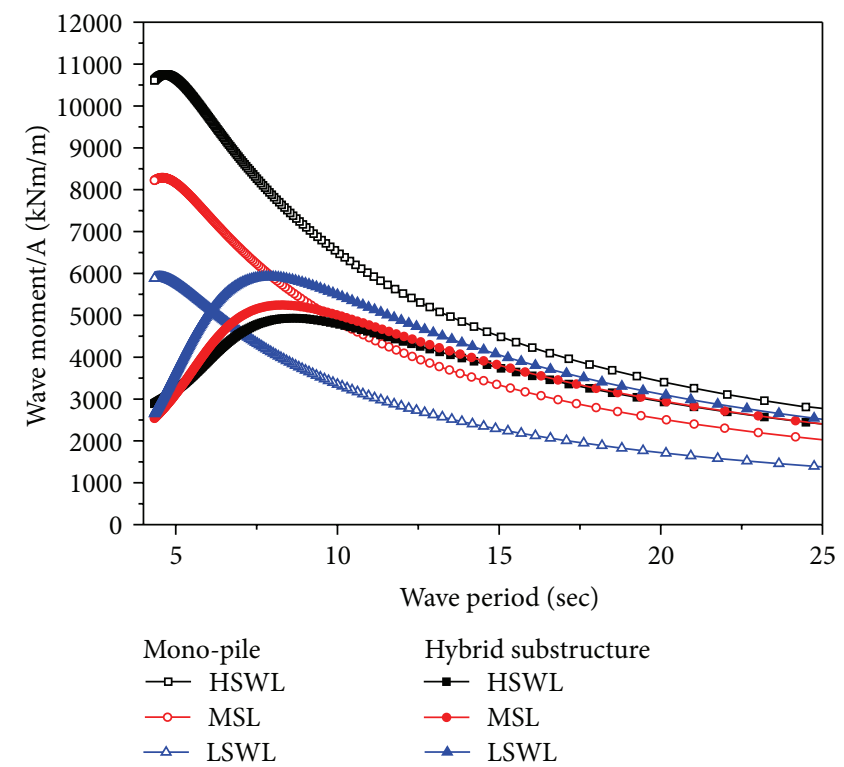

Figure 5: Comparison of wave moments for various water depths.

TABLE 7: Stiffness for $F_{x}$ versus $U_{x}\left(F_{y}\right.$ versus $\left.U_{y}\right)$.

\begin{tabular}{lc}
\hline Displacement, $U_{x}(\mathrm{~m})$ & Load, $F_{x}(\mathrm{~N})$ \\
\hline 0 & 0 \\
0.0015 & $1.127 \times 10^{6}$ \\
0.00319 & $2.255 \times 10^{6}$ \\
0.00494 & $3.382 \times 10^{6}$ \\
0.00672 & $4.510 \times 10^{6}$ \\
0.00852 & $5.637 \times 10^{6}$ \\
0.0103 & $6.764 \times 10^{6}$ \\
0.0122 & $7.892 \times 10^{6}$ \\
0.014 & $9.019 \times 10^{6}$ \\
0.0159 & $1.015 \times 10^{7}$ \\
0.0179 & $1.127 \times 10^{7}$ \\
\hline
\end{tabular}

North Sea Wave Project by Hasselmann et al. [13] based on the fact that the wave spectrum is never fully developed. These authors suggested using the family of JONSWAP wave spectra in the design of an offshore structure in a fetch limited area. Therefore, the JONSWAP wave spectrum is applicable to this study. Here also, a safety factor of 1.35 is applied for all cases. The structural results for various water depths are summarized in Table 14. The largest displacement is observed at HSWL. The difference in the displacement at HSWL between pile-soil interaction condition and fixed condition is about
TABle 8: Stiffness for $F_{z}$ versus $U_{z}$.

\begin{tabular}{lc}
\hline Displacement, $U_{z}(\mathrm{~m})$ & Load, $F_{z}(\mathrm{~N})$ \\
\hline 0 & 0 \\
$3.47 \times 10^{-4}$ & $2.063 \times 10^{6}$ \\
$6.93 \times 10^{-4}$ & $4.126 \times 10^{6}$ \\
0.00105 & $6.189 \times 10^{6}$ \\
0.00142 & $8.252 \times 10^{6}$ \\
0.00178 & $1.031 \times 10^{7}$ \\
0.00214 & $1.238 \times 10^{7}$ \\
0.0025 & $1.444 \times 10^{7}$ \\
0.00286 & $1.650 \times 10^{7}$ \\
0.00323 & $1.857 \times 10^{7}$ \\
0.00359 & $2.063 \times 10^{7}$ \\
\hline
\end{tabular}

$0.0077 \mathrm{~m}$ and is smaller than the minimum displacement under pile-soil interaction condition. The dynamic responses exhibit different patterns according to the wave depth and the displacement is strongly influenced by the soil conditions. The structural displacement and the bending moment at HSWL are plotted in Figures 12-15 for various soil conditions.

The structural members and the joints connecting two or more structural members should be checked according to recognized standard. In the present study, ISO 19902 [14] is used for the check of the hybrid substructure under extreme 


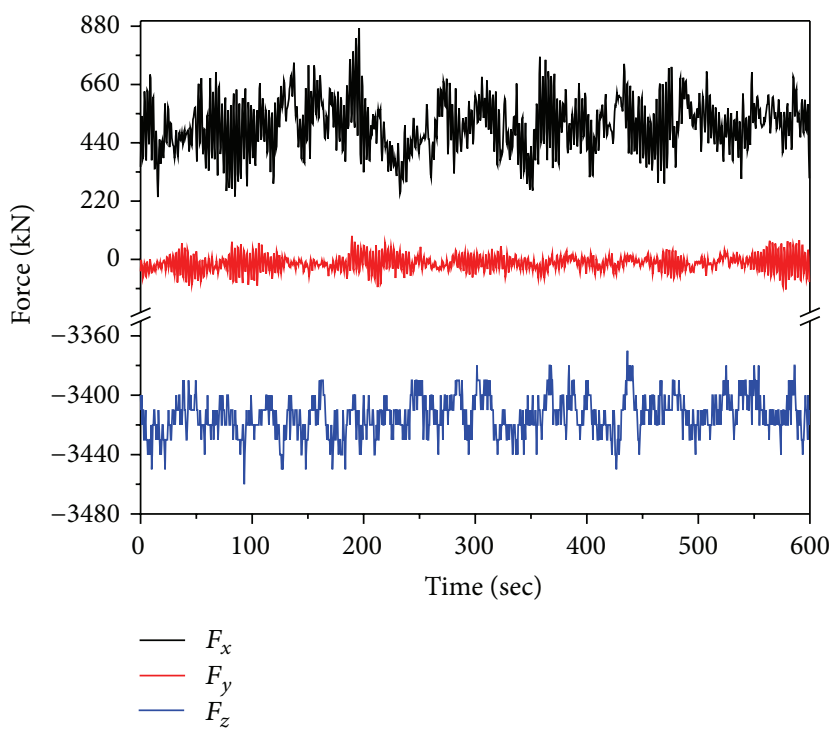

FIgURE 6: Wind forces at TP for DLC 6.2ja-2.

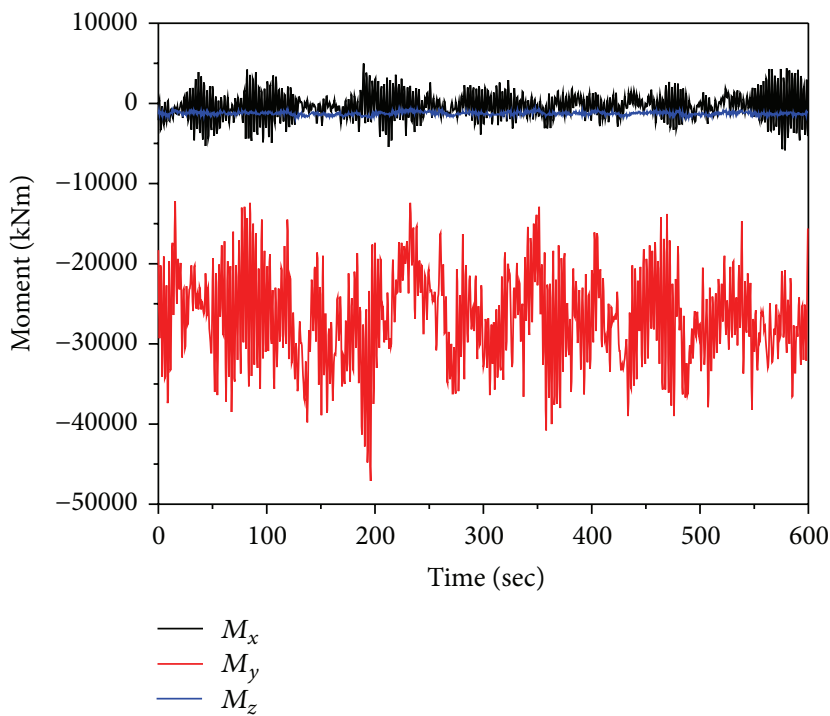

Figure 7: Wind moments at TP for DLC 6.2ja-2.

TABLE 9: Stiffness for $M_{x}$ versus $R_{x}\left(M_{y}\right.$ versus $\left.R_{y}\right)$.

\begin{tabular}{lc}
\hline Displacement, $R_{x}(\mathrm{rad})$ & Load, $M_{x}(\mathrm{Nm})$ \\
\hline 0 & 0 \\
$1.31 \times 10^{-4}$ & $2.200 \times 10^{7}$ \\
$2.65 \times 10^{-4}$ & $4.401 \times 10^{7}$ \\
$4.01 \times 10^{-4}$ & $6.601 \times 10^{7}$ \\
$5.47 \times 10^{-4}$ & $8.801 \times 10^{7}$ \\
$6.99 \times 10^{-4}$ & $1.10 \times 10^{8}$ \\
$9.41 \times 10^{-4}$ & $1.32 \times 10^{8}$ \\
0.0012 & $1.54 \times 10^{8}$ \\
0.00153 & $1.76 \times 10^{8}$ \\
0.00189 & $1.98 \times 10^{8}$ \\
0.00225 & $2.20 \times 10^{8}$ \\
\hline
\end{tabular}

TABLE 10: Stiffness for $M_{z}$ versus $R_{z}$.

\begin{tabular}{lc}
\hline Displacement, $R_{z}(\mathrm{rad})$ & Load, $M_{z}(\mathrm{Nm})$ \\
\hline 0 & 0 \\
1.0 & $2.21 \times 10^{9}$ \\
\hline
\end{tabular}

design condition and a value of $250 \mathrm{MPa}$ is adopted for the yield stress of steel. Tables 15-18 show the member unity checks and the joint unity checks for various water depths. The values under regular wave are larger than those under irregular wave. The values with pile-soil condition are larger than those with fixed condition for regular wave but happen to be smaller in case of irregular wave. The values at MSL are the largest for regular wave condition and the values at HSWL are the largest for irregular wave condition. This means that 


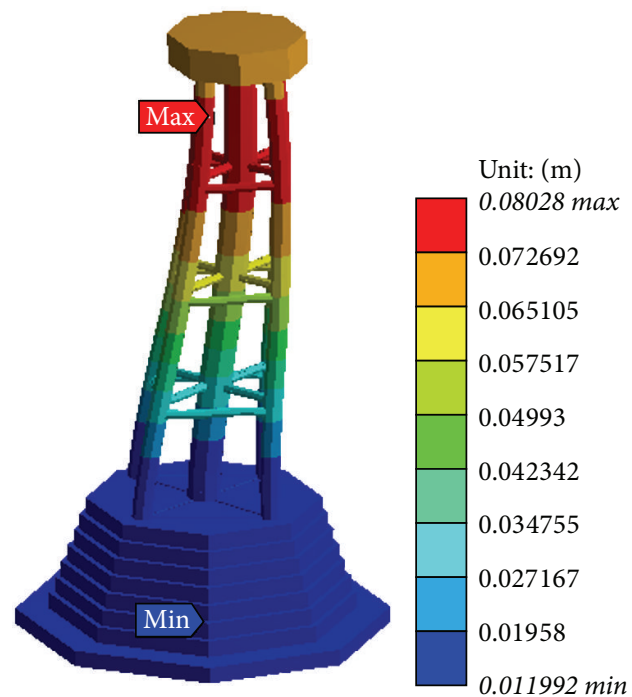

(a) Pile-soil condition

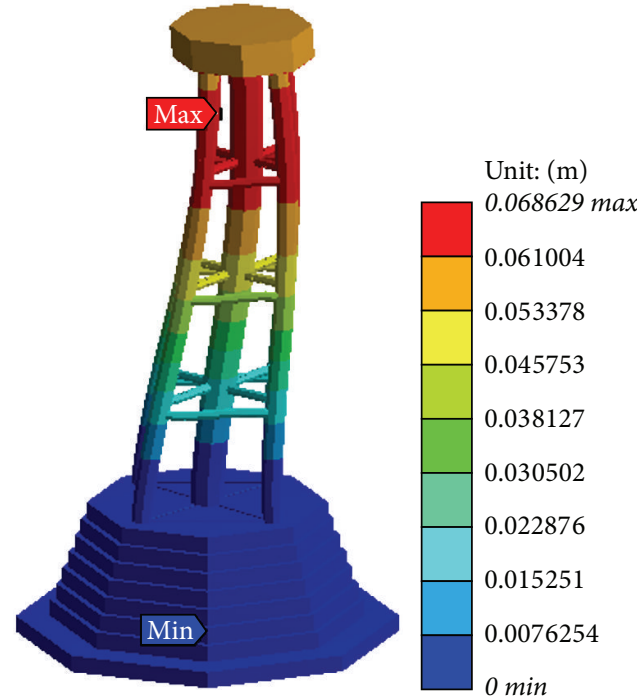

(b) Fixed condition

FIGURE 8: Comparison of displacements with regular wave at MSL.

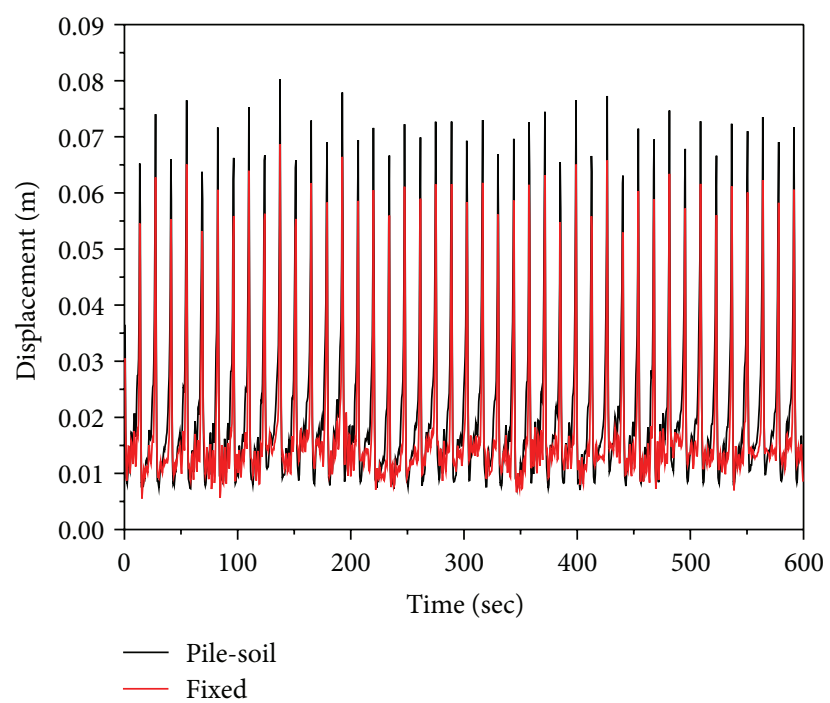

FIgURE 9: Maximum displacements with regular wave at MSL.

TABLE 11: Natural frequencies of hybrid substructure (Hz).

\begin{tabular}{lccc}
\hline Mode & $\begin{array}{c}\text { Pile-soil } \\
\text { interaction }\end{array}$ & $\begin{array}{c}\text { Fixed } \\
\text { condition }\end{array}$ & Difference (\%) \\
\hline 1 & 0.375 & 0.392 & 4.3 \\
2 & 0.377 & 0.394 & 4.3 \\
3 & 0.867 & 1.209 & 28.2 \\
4 & 0.886 & 1.873 & 52.6 \\
5 & 1.534 & 1.873 & 18.0 \\
6 & 1.534 & 2.043 & 24.9 \\
7 & 1.888 & 2.256 & 16.3 \\
8 & 2.060 & 4.330 & 52.4 \\
9 & 2.641 & 5.179 & 49.0 \\
10 & 2.641 & 5.179 & 49.0 \\
\hline
\end{tabular}

the dynamic response of the hybrid substructure is strongly influenced by the wave conditions. The member unity checks for yield 2 at MSL and the joint unity checks for combined (axial + bending) at HSWL are plotted in Figures 16 and 17, respectively. Noting that a value less than 1.0 indicates the satisfaction of the recognized standard, it appears that the structural members and the joints of the hybrid substructure system satisfy the ULS design condition in all cases.

\section{Conclusions}

The hybrid substructure for $3 \mathrm{MW}$ offshore wind turbine is newly suggested to reduce the wave forces acting on the substructure and to increase the stability against overturning moment. The comparison of the wave forces and moments 
TABLE 12: Extreme values at TP due to extreme wind.

\begin{tabular}{lccccccccc}
\hline & & Load case & $M_{z}(\mathrm{kN} \cdot \mathrm{m})$ & $M_{y}(\mathrm{kN} \cdot \mathrm{m})$ & $M_{x}(\mathrm{kN} \cdot \mathrm{m})$ & $F_{z}(\mathrm{kN})$ & $F_{y}(\mathrm{kN})$ & $F_{x}(\mathrm{kN})$ & Safety factor \\
\hline$M_{x}$ & Max & DLC2.2cc+6 & 9456.5 & 18087 & 13125 & -3827.3 & 225.9 & -318.4 \\
$M_{x}$ & Min & DLC2.2cc+6 & -10008 & -8834.0 & -22000 & -3665.7 & -378.1 & 138.2 \\
$M_{y}$ & Max & DLC6.2cc-6 & 1866.1 & 51227 & 9174.7 & -3738.2 & 214.1 & -927.3 & 1.10 \\
$M_{y}$ & Min & DLC6.2ja-2 & -1830.9 & -52925 & -1609.6 & -3749.0 & -38.1 & 969.4 \\
$M_{z}$ & Max & DLC1.4af2 & 283.4 & 3677.1 & 46109 & -4652.0 & 729.5 & -8.73 & 1.10 \\
$M_{z}$ & Min & DLC1.4bf2 & -2726.2 & -10127 & -47158 & -4580.9 & -629.8 & 177.0 & 1.35 \\
$M_{y z}$ & Max & DLC6.2ja-2 & -1830.9 & -52925 & -1609.6 & -3749.0 & -38.1 & 969.4 & 1.10 \\
$M_{y z}$ & Min & DLC2.2da+7 & 47.3 & 0.16 & 2.11 & -3726.7 & 15.4 & -1.03 & 1.10 \\
$F_{x}$ & Max & DLC7.1aa6-5 & -5.34 & -192.6 & 11270 & -3510.0 & 236.5 & -9.91 & 1.10 \\
$F_{x}$ & Min & DLC1.1k-2 & 3983.2 & 4726.5 & 29063 & -5254.3 & 460.3 & -11.2 \\
$F_{y}$ & Max & DLC1.1g-1 & -419.8 & 2944.5 & 44202 & -5152.8 & 756.1 & -4.80 & 1.50 \\
$F_{y}$ & Min & DLC1.4bf4 & -3216.8 & -10304 & -46468 & -4557.8 & -654.2 & 179.2 & 1.50 \\
$F_{z}$ & Max & DLC6.2ja-2 & -1831.3 & -52815 & -1962.0 & -3755.3 & -45.4 & 970.4 & 1.10 \\
$F_{z}$ & Min & DLC6.2dc-3 & 1928.2 & 50715 & -1722.4 & -3789.9 & -2.68 & -942.4 & 1.10 \\
$F_{y z}$ & Max & DLC6.2ja-2 & -1831.3 & -52815 & -1962.0 & -3755.3 & -45.4 & 970.4 & 1.10 \\
$F_{y z}$ & Min & DLC2.1ab3+6 & 17.8 & -89.3 & -505.1 & -4597.6 & -0.015 & 0.013 & 1.35 \\
\hline
\end{tabular}

TABLE 13: Structural results under regular wave condition.



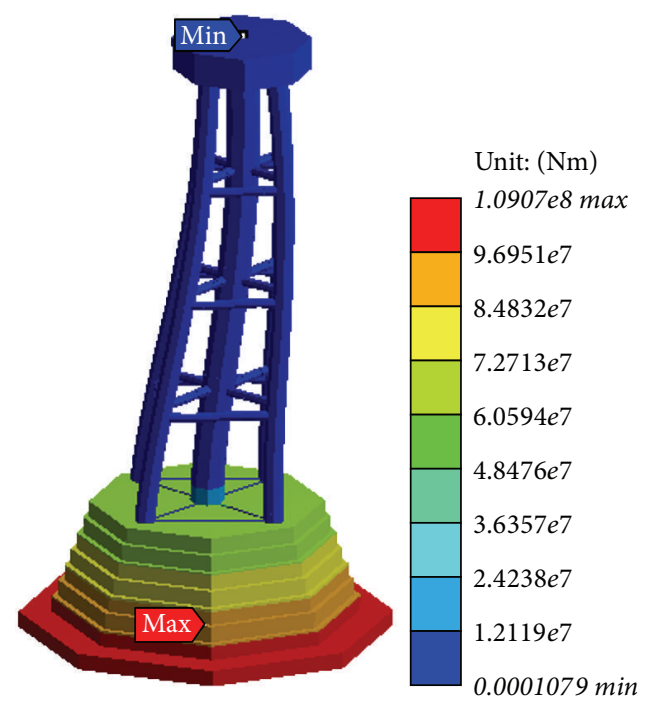

(a) Pile-soil condition

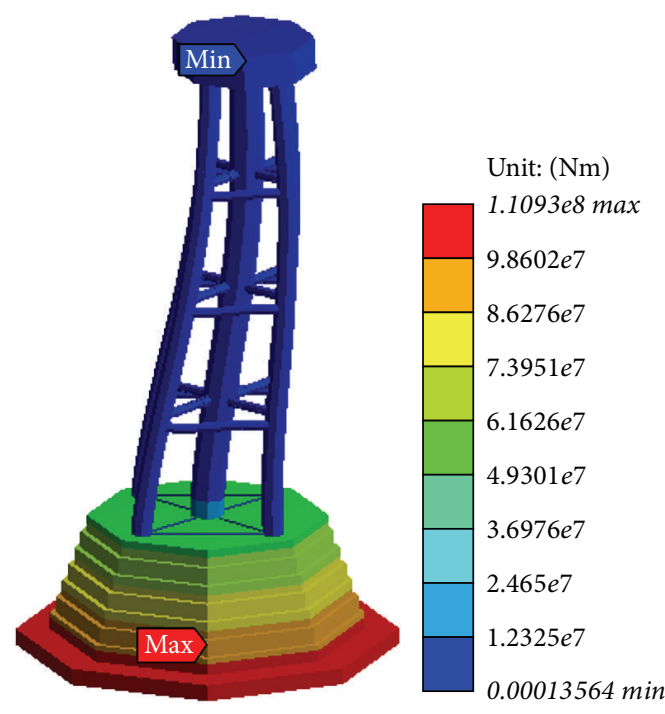

(b) Fixed condition

FIGURE 10: Comparison of bending moments with regular wave at MSL. 
TABLE 14: Structural results under irregular wave condition.

\begin{tabular}{|c|c|c|c|c|c|c|c|}
\hline & & \multicolumn{2}{|c|}{ LSWL } & \multicolumn{2}{|c|}{ MSL } & \multicolumn{2}{|c|}{ HSWL } \\
\hline & & Pile-soil & Fixed & Pile-soil & Fixed & Pile-soil & Fixed \\
\hline \multirow{2}{*}{ Displacement (m) } & $\operatorname{Max}$ & 0.0340 & 0.0251 & 0.0378 & 0.0305 & 0.0437 & 0.0359 \\
\hline & Min & 0.0093 & 0.0000 & 0.0084 & 0.0000 & 0.0092 & 0.0000 \\
\hline \multirow{2}{*}{ Axial force $(\mathrm{MN})$} & Max & 2.2824 & 2.8266 & 2.2828 & 2.8335 & 2.847 & 2.847 \\
\hline & Min & -82.77 & -82.767 & -10.092 & -10.091 & -119.06 & -119.06 \\
\hline \multirow{2}{*}{ Shear force $(\mathrm{MN})$} & Max & 7.2287 & 10.787 & 6.1829 & 9.1615 & 8.0996 & 8.0999 \\
\hline & Min & 0.0000 & 0.0000 & 0.0000 & 0.0000 & 0.0000 & 0.0000 \\
\hline \multirow{2}{*}{ Bending moment $(\mathrm{MN} \cdot \mathrm{m})$} & Max & 34.109 & 46.133 & 33.927 & 42.136 & 45.724 & 45.727 \\
\hline & Min & 0.0000 & 0.0001 & 0.0000 & 0.0000 & 0.0000 & 0.0000 \\
\hline \multirow{2}{*}{ Torsional moment $(\mathrm{MN} \cdot \mathrm{m})$} & Max & 2.3784 & 2.3785 & 2.3786 & 2.379 & 2.38 & 2.38 \\
\hline & Min & -2.3167 & -2.3168 & -2.317 & -2.3174 & -2.3185 & -2.3185 \\
\hline
\end{tabular}

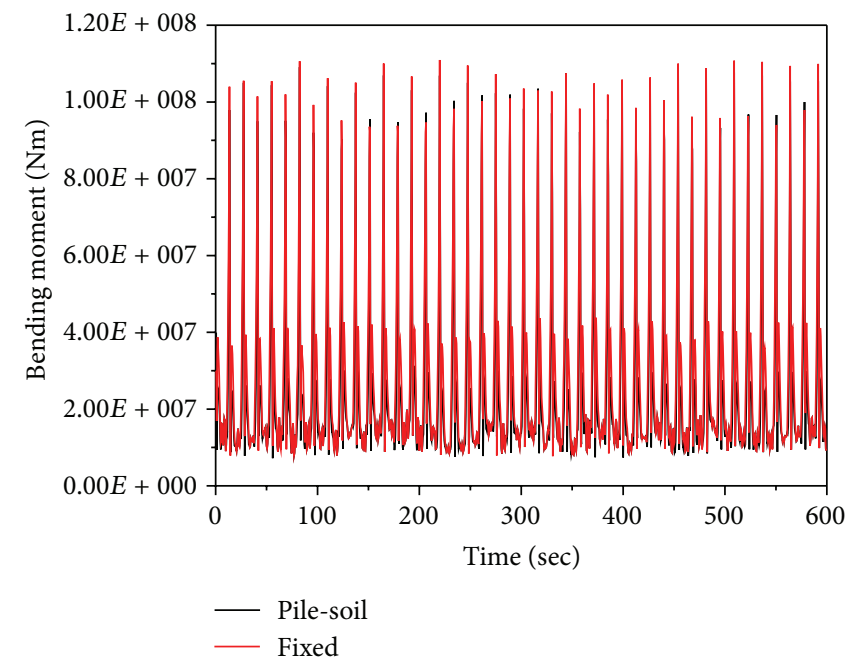

FIGURE 11: Maximum bending moments with regular wave at MSL.

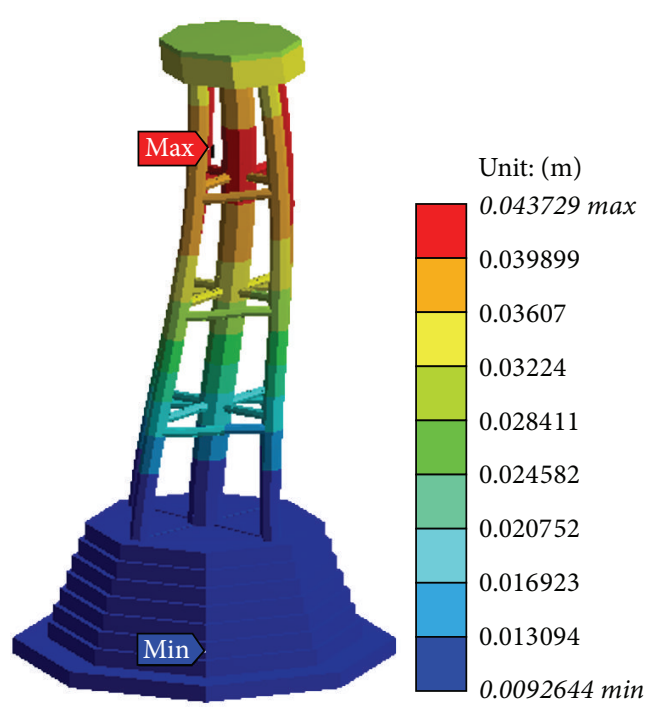

(a) Pile-soil condition

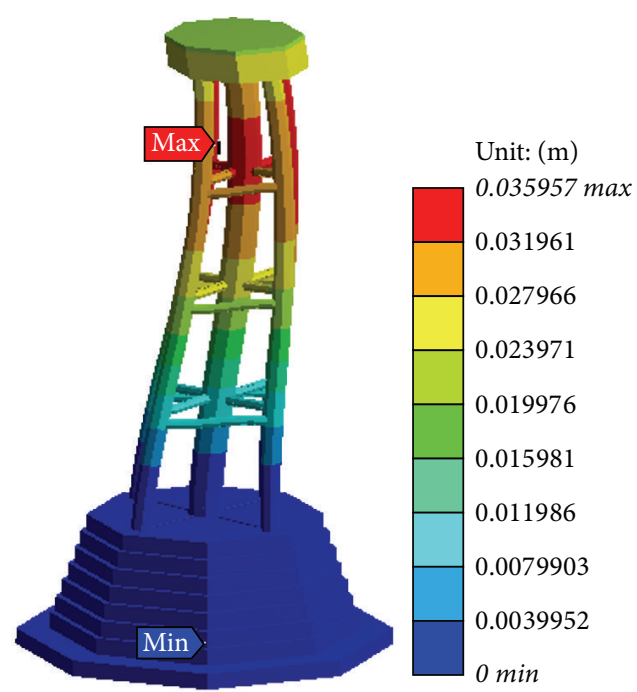

(b) Fixed condition

FIGURE 12: Comparison of displacements with irregular wave at HSWL. 
TABLE 15: Member unity checks for regular wave.

\begin{tabular}{|c|c|c|c|c|c|c|}
\hline & \multicolumn{2}{|c|}{ LSWL } & \multicolumn{2}{|c|}{ MSL } & \multicolumn{2}{|c|}{ HSWL } \\
\hline & Pile-soil & Fixed & Pile-soil & Fixed & Pile-soil & Fixed \\
\hline Axial & 0.14359 & 0.14354 & 0.14295 & 0.14269 & 0.13998 & 0.13998 \\
\hline Shear & 0.19755 & 0.19487 & 0.27729 & 0.27351 & 0.24710 & 0.24710 \\
\hline Bending & 0.52860 & 0.51713 & 0.61652 & 0.60624 & 0.53309 & 0.53309 \\
\hline Torsion & 0.02232 & 0.02232 & 0.02232 & 0.02232 & 0.02232 & 0.02232 \\
\hline Yield 1 & 0.39809 & 0.39115 & 0.58153 & 0.57361 & 0.50640 & 0.50640 \\
\hline Yield 2 & 0.59662 & 0.58563 & 0.68441 & 0.67472 & 0.59856 & 0.59857 \\
\hline
\end{tabular}

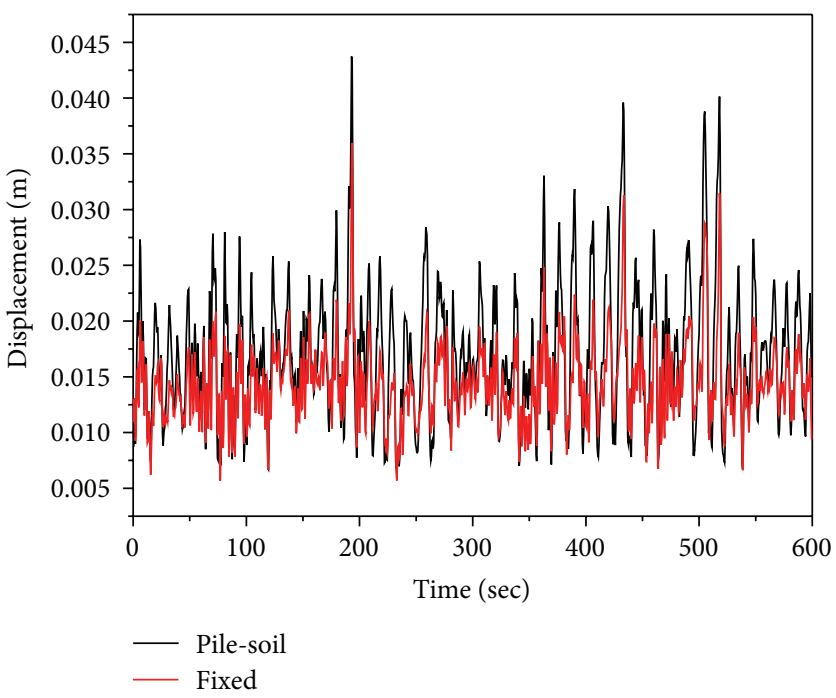

FIGURE 13: Maximum displacements with irregular wave at HSWL.

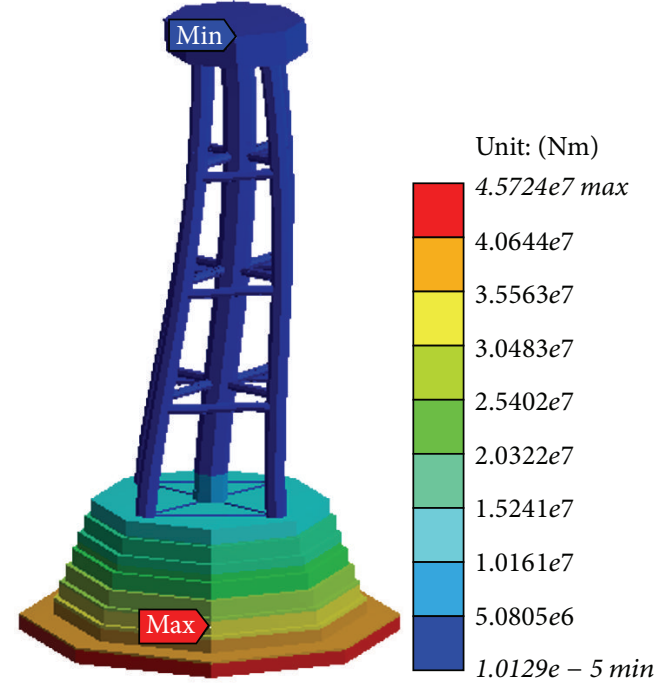

(a) Pile-soil condition

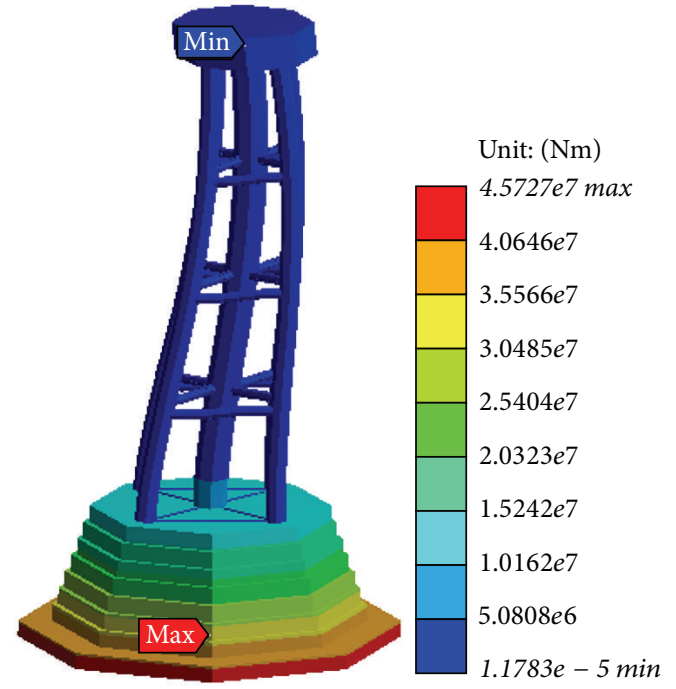

(b) Fixed condition

FIGURE 14: Comparison of bending moments with irregular wave at HSWL.

between the hybrid substructure and the mono-pile revealed that installing the multicylinder near free surface can be effective for decreasing the wave forces and installing the gravity-based substructure at the seabed can be very effective for increasing the stability against overturning moment. The structural analysis of the hybrid substructure was carried out by ANSYS ASAS for various wave conditions using the wind forces obtained from GH-Bladed and the stiffness matrices for pile-soil foundation system and showed that the dynamic responses of the hybrid substructure were strongly influenced 
TABLE 16: Member unity checks for irregular wave.

\begin{tabular}{lcccccr}
\hline & LSWL & & & MSL & & HSWL \\
& Pile-soil & Fixed & Pile-soil & Fixed & Pile-soil & 0.15154 \\
Axial & 0.15328 & 0.15321 & 0.15296 & 0.15275 & 0.15154 \\
Shear & 0.10457 & 0.10489 & 0.13127 & 0.13303 & 0.16797 \\
Bending & 0.23846 & 0.24313 & 0.29839 & 0.30532 & 0.34586 \\
Torsion & 0.02626 & 0.02626 & 0.02626 & 0.02626 & 0.02626 & 0.34586 \\
Yield 1 & 0.26791 & 0.26798 & 0.26823 & 0.26844 & 0.02626 \\
Yield 2 & 0.30494 & 0.30978 & 0.36472 & 0.37194 & 0.41247 \\
\hline
\end{tabular}

TABLE 17: Joint unity checks for regular wave.

\begin{tabular}{|c|c|c|c|c|c|c|}
\hline & \multicolumn{2}{|c|}{ LSWL } & \multicolumn{2}{|c|}{ MSL } & \multicolumn{2}{|c|}{ HSWL } \\
\hline & Pile-soil & Fixed & Pile-soil & Fixed & Pile-soil & Fixed \\
\hline Axial & 0.05868 & 0.05920 & 0.03708 & 0.03753 & 0.02884 & 0.02884 \\
\hline In-plane bending & 0.75487 & 0.74347 & 0.94235 & 0.94135 & 0.92134 & 0.92134 \\
\hline Out-of-plane bending & 0.11832 & 0.11895 & 0.11375 & 0.01131 & 0.09605 & 0.09605 \\
\hline Combined (axial + bending) & 0.69249 & 0.67478 & 0.96058 & 0.96008 & 0.94048 & 0.94049 \\
\hline
\end{tabular}

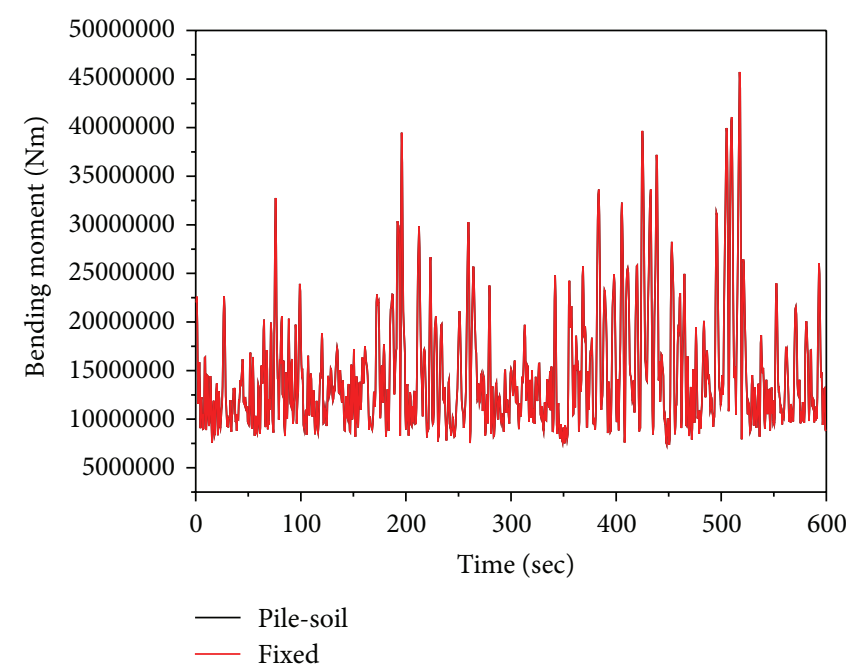

FIGURE 15: Maximum bending moments with irregular wave at HSWL.

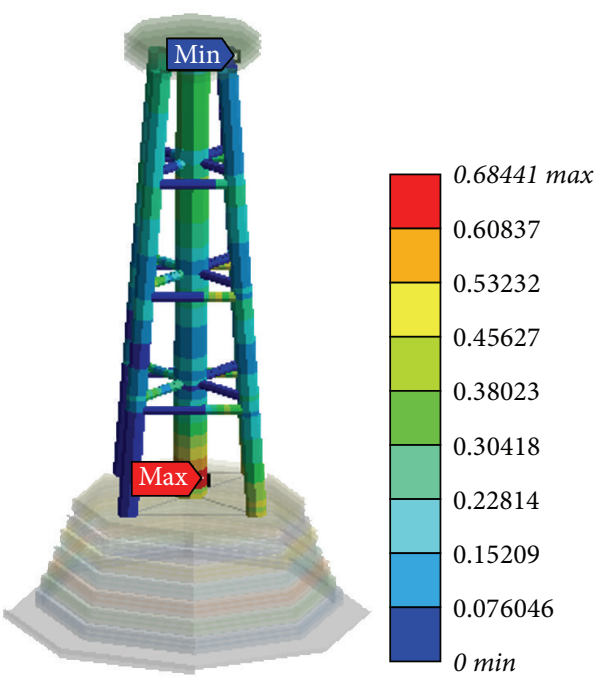

(a) Regular wave

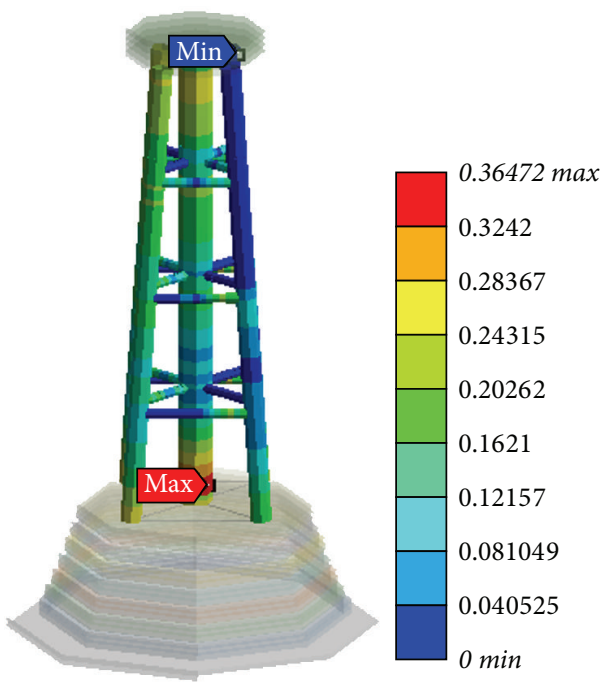

(b) Irregular wave

FIGURE 16: Member unity checks for yield 2 at MSL. 
TABLE 18: Joint unity checks for irregular wave.

\begin{tabular}{lcccccc}
\hline & \multicolumn{2}{c}{ LSWL } & \multicolumn{2}{c}{ MSL } & \multicolumn{2}{c}{ HSWL } \\
& Pile-soil & Fixed & Pile-soil & Fixed & Pile-soil & Fixed \\
\hline Axial & 0.02433 & 0.02420 & 0.02161 & 0.02181 & 0.02121 & 0.02121 \\
In-plane bending & 0.37216 & 0.37455 & 0.48123 & 0.48824 & 0.61702 \\
Out-of-plane bending & 0.06896 & 0.07041 & 0.06833 & 0.06973 & 0.07128 & 0.07128 \\
Combined (axial + bending) & 0.20636 & 0.20991 & 0.30202 & 0.30911 & 0.44869 & 0.44870 \\
\hline
\end{tabular}

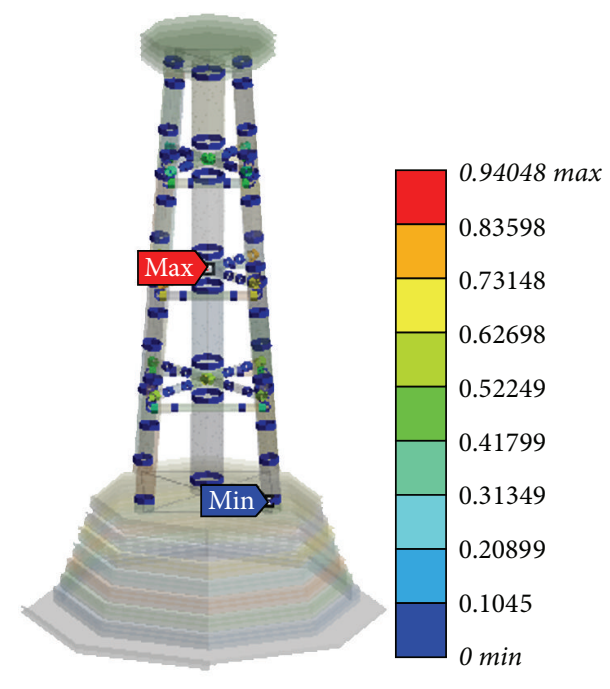

(a) Regular wave

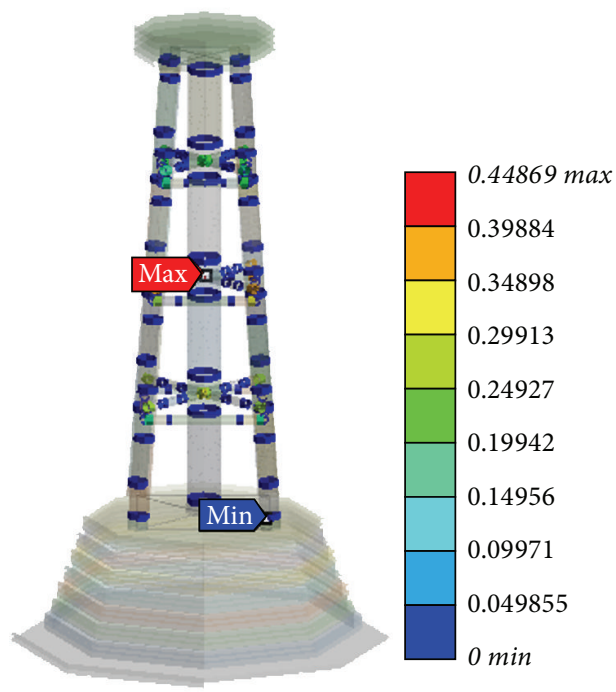

(b) Irregular wave

FIGURE 17: Joint unity checks for combined (axial + bending) at HSWL.

by the soil conditions (Table 6) and the wave conditions. The hybrid substructure system was also seen to secure structural safety with respect to ULS (ultimate limit state) design condition for all wave conditions. In addition, the comparison of the first natural frequency with $1 \mathrm{P}$ and $3 \mathrm{P}$ frequencies showed that the hybrid substructure exhibited soft-stiff design properties and indicated that resonance between the wind turbine and the hybrid substructure would not occur. Consequently, the suggested hybrid substructure can be effective for reducing the hydrodynamic effects and construction costs for the future wind turbines to be installed in the southwestern sea of South Korea.

\section{Competing Interests}

The authors declare that there are no competing interests regarding the publication of this paper.

\section{Acknowledgments}

This research was supported by Korea Institute of Energy Technology Evaluation and Planning through the research projects "Development of hybrid substructure systems for offshore wind farm (20123010020110)" and "Development of $3 \mathrm{~kW}$ cylindrical wave energy system with horizontal rotation for increasing gross generation (20153030071630)."

\section{References}

[1] M. Klose, P. Dalhoff, and K. Argyriadis, "Integrated load and strength analysis for offshore wind turbines with jacket structures," in Proceedings of the European Offshore Wind Energy Conference and Exhibition, Berlin, Germany, December 2007.

[2] J. Weinzettel, M. Reenaas, C. Solli, and E. G. Hertwich, "Life cycle assessment of a floating offshore wind turbine," Renewable Energy, vol. 34, no. 3, pp. 742-747, 2009.

[3] J. M. Jonkman, "Dynamics of offshore floating wind turbinesmodel development and verification," Wind Energy, vol. 12, no. 5, pp. 459-492, 2009.

[4] Z. Gao, N. L. J. Saha, T. Moan, and J. Amdahl, "Dynamic analysis of offshore fixed wind turbines under wind and wave loads using alternative computer codes," in Proceedings of the $3 \mathrm{rd}$ TORQUE Conference, Crete, Greece, 2010.

[5] D. Kaufer, T. Fischer, F. Vorpahl, W. Popko, and M. Kühn, "Different approaches to modeling jacket support structures and their impact on overall wind turbine dynamics," in Proceedings of the 10th German wind Energy Conference (DEWEK '10), Bremen, Germany, 2010.

[6] E. Lozano-Minguez, A. J. Kolios, and F. P. Brennan, "Multicriteria assessment of offshore wind turbine support structures," Renewable Energy, vol. 36, no. 11, pp. 2831-2837, 2011.

[7] M. B. Zaaijer, "Comparison of monopile, tripod, suction bucket and gravity base design for a $6 \mathrm{MW}$ turbine," in Proceedings of the Offshore Wind Energy in Mediterranean and Other European Seas Conference, Naples, Italy, 2003. 
[8] S. Føreland, M. O. Rastad, and K. Aas-Jacobsen, "A parametric study on fixed bottom wind turbines in the North Sea," in Proceedings of the Nordic Steel Construction Conference, p. 831, Oslo, Norway, September 2012.

[9] M.-S. Park, Y.-J. Jeong, and Y.-J. You, "Structural analysis of a hybrid substructure with multi-cylinder for $5 \mathrm{MW}$ offshore wind turbines," in Proceedings of the ASME 33rd International Conference on Ocean, Offshore and Arctic Engineering (OMAE '14), San Francisco, Calif, USA, June 2014.

[10] IEC, "Wind turbines-part 3: design requirements for offshore wind turbines," IEC 61400-3, International Electrotechnical Commission, 2009.

[11] W. Shi, J. H. Han, C. W. Kim, D. Y. Lee, H. K. Shin, and H. C. Park, "Feasibility study of offshore wind turbine substructures for southwest offshore wind farm project in Korea," Renewable Energy, vol. 74, pp. 406-413, 2014.

[12] J. G. Espinosa, "Design and calculus of the foundation structure of an offshore monopile wind turbine," Polytechnic University of Catalonia, Barcelona, Spain, 2012.

[13] K. Hasselmann, W. Sell, D. B. Ross, and P. Müller, "A parametric wave prediction model," Journal of Physical Oceanography, vol. 6, no. 2, pp. 200-228, 1976.

[14] ISO, "Petroleum and natural gas industries—fixed steel offshore structures," ISO 19902, International Organization for Standardization, Geneva, Switzerland, 2007. 

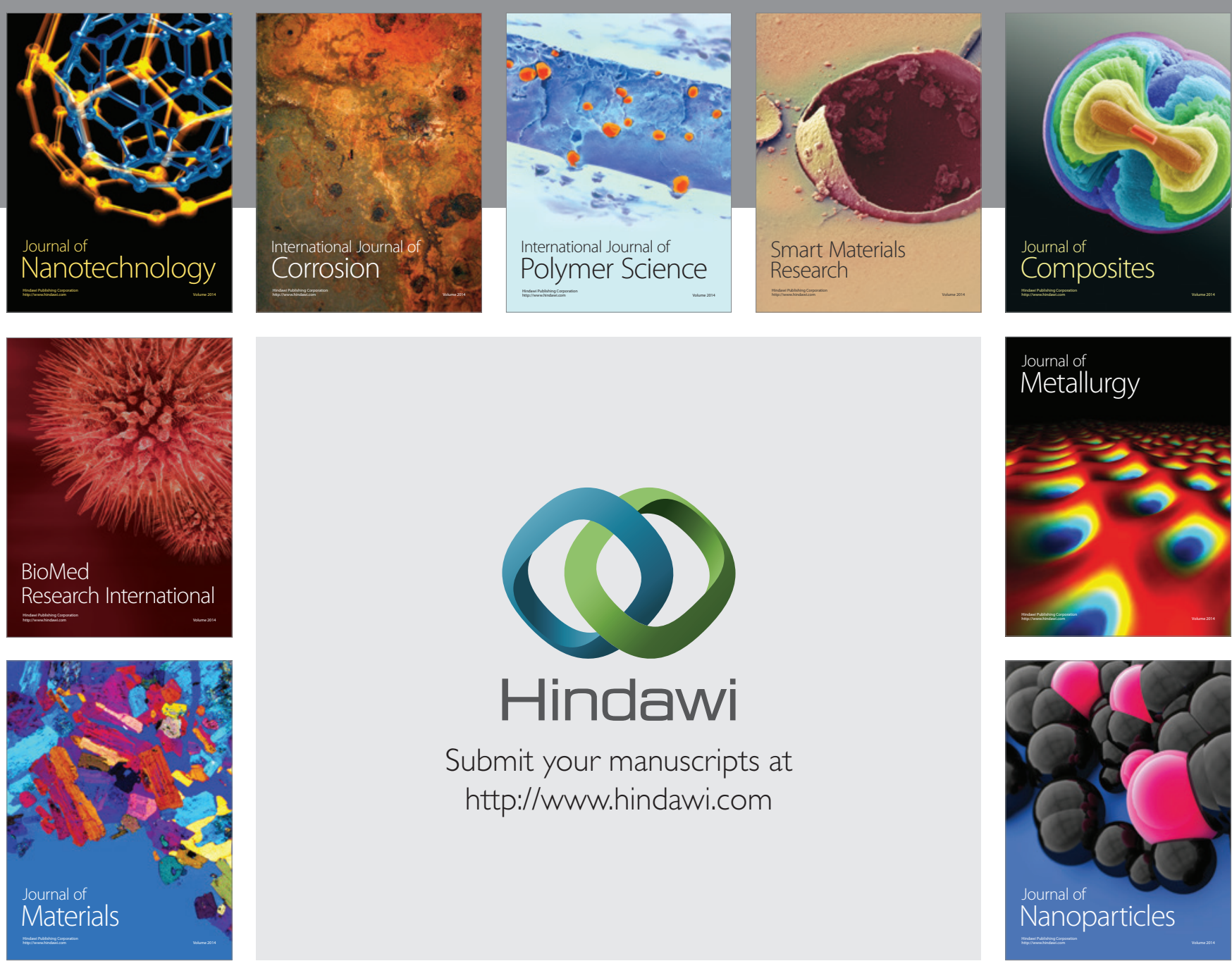

\section{Hindawi}

Submit your manuscripts at

http://www.hindawi.com

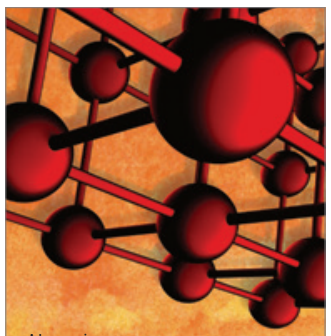

Materials Science and Engineering
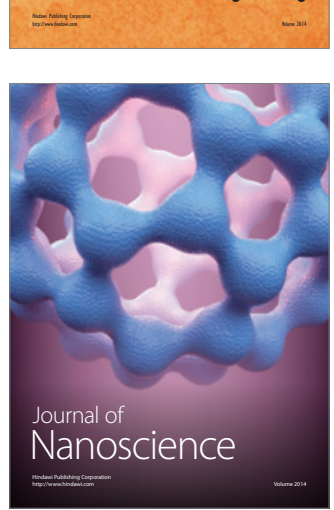
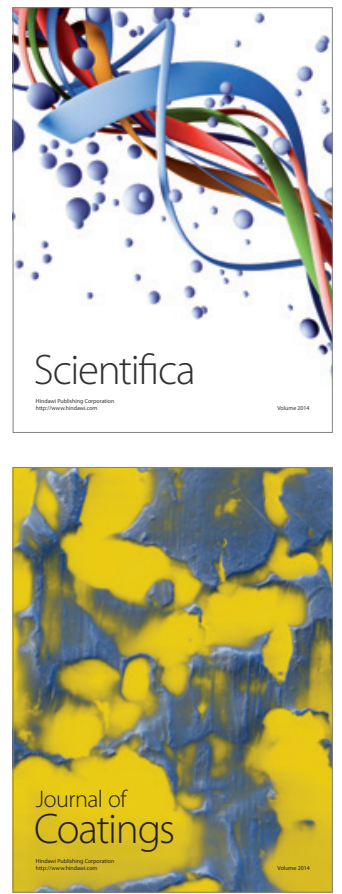
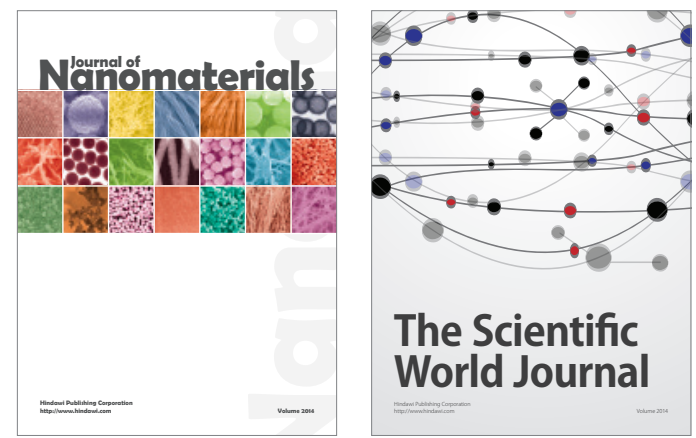

The Scientific World Journal
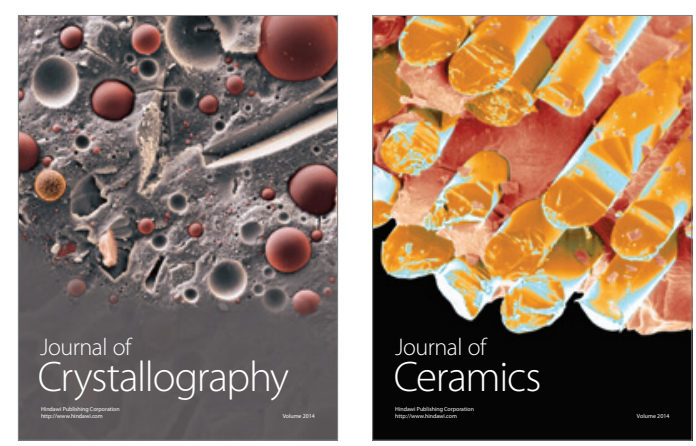
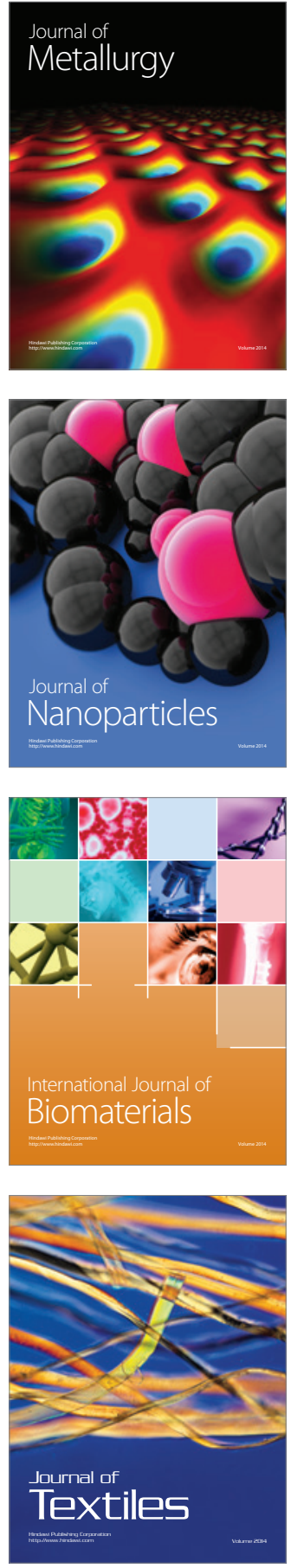